expenditure. Calorie balance in this instance was achieved, not on a daily or monthly basis, but only over a period of a year.

These results indicate the need for further studies, combining energy-expenditure measurements with food-intake records, on people following different occupations. The two sides of the inquiry illumine each other: the one does not replace the other.

\title{
REFERENCES
}

Douglas, C. G. (191 I). भ. Physiol. 42, xvii.

Douglas, C. G. (1956). Proc. Nutr. Soc. 15, 72.

Edholm, O. G. \& Fletcher, J. G. (1955). F. Physiol. 128, I 8 P.

Edholm, O. G., Fletcher, J. G., Widdowson, E. M. \& McCance, R. A. (1955). Brit. F. Nutr. 9, 286.

Fox, R. H. (1953). A study of energy expenditure of Africans engaged in various rural activities. Thesis submitted for the Ph.D. Degree, University of London.

Garry, R. C., Passmore, R., Warnock, G. M. \& Durnin, J. V. G. A. (1955). Spec. Rep. Ser. med. Res. Coun., Lond., no. 289.

Kofrányi, E. \& Michaelis, H. F. (r940). Arbeitsphysiologie, 11, 148.

Widdowson, E. M., Edholm, O. G. \& McCance, R. A. (1954). Brit. F. Nutr. 8, 147.

Wolff, H. S. (1956). Proc. Nutr. Soc. 15, 77.

\section{Daily energy expenditure by man}

\section{By R. Passmore, Department of Physiology, University of Edinburgh}

'The greatest mystery about a human being is not his reaction to sex or praise, but the manner in which he contrives to put in twenty four hours a day. It is this which puzzles the longshoreman about the clerk, the Londoner about the Bushman. It was this that puzzled Carol in regard to the married Vida.' (Sinclair Lewis in Main Street).

In western Europe, in North America, in Australia and in New Zealand the daily energy expenditure of large numbers of the population is less than the energy derived from their food. In consequence the people become fat. In Asia, in Africa and in many countries in Latin America the food supply is insufficient to meet the energy needs of daily life. As a result many persons in these countries are thin: they also become lethargic. There is a consensus of medical opinion that such calorie imbalances, the positive and the negative, are both detrimental to health and working efficiency. Our civilizations are failing either to disperse people throughout the world to the agricultural sources of available food or, alternatively, to distribute foods by the mechanism of international trade according to the physiological needs of the population. The latest data from FAO (1955) presented in Table $\mathrm{I}$ indicate that the disproportions in the distribution of food are increasing rather than diminishing. Whatever the physiological yardstick of calorie needs, many persons in North America and western Europe eat beyond the mark and vast numbers in the Far East and Latin America can have no chance to obtain a sufficiency of foods for their needs.

Hitherto estimates of calorie needs have been based predominantly on the results of measurements of calorie intake determined by dietary surveys. This procedure 
Table I. Average calorie intake (Cal./head/day) in various regions of the world $(F A O$, 1955)

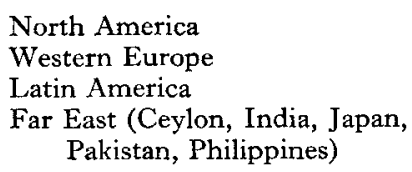

$\begin{array}{cccc}\text { Prewar } & 1946-7 & 1950-1 & 1953-4 \\ 3120 & 3200 & 3170 & 3080 \\ 2890 & 2500 & 2790 & 2840 \\ 2200 & 2330 & 2380 & 2380 \\ 2000 & 1730 & 1760 & 1850\end{array}$

involves the assumption that the intake of energy is sufficient and satisfactory for physiological needs. Such an assumption is often unjustified. Clearly data provided by surveys of daily energy expenditure could give an additional guide to calorie requirements of population groups for health and working efficiency.

Recently in Great Britain attempts have been made to measure energy expenditure of persons carrying out their every-day life for periods of a week or longer. Edholm (1956) (see also Edholm, Fletcher, Widdowson \& McCance, 1955) has already given some account of the surveys showing how some of our soldiers spent their time and energy. He has also referred to the similar study on clerks and miners (Garry, Passmore, Warnock \& Durnin, 1955). I would like now to discuss some of our findings and their implications for the assessment of physiological calorie needs.

Table 2 gives a summary of our main results. The data were obtained over a whole working week and include the week-end. Normal working time was an $8 \mathrm{~h}$ day and a $5 \frac{1}{2}$-day week, but there was some overtime. As a result the average working time was $47 \mathrm{~h} \mathrm{I} 4 \mathrm{~min}$ a week for the miners, and $49 \mathrm{~h} 53 \mathrm{~min}$ for the clerks. The figures for energy expenditure in Table 2 are thus a little less than those for a normal working day without overtime.

Table 2. Average daily expenditure of energy (Cal.) by ten clerks (age 28.3 years, weight $64.6 \mathrm{~kg}$ ) and by nineteen miners (age 33.6 years, weight $65.7 \mathrm{~kg}$ ), as measured over a whole week by Garry et al. (1955)

\begin{tabular}{|c|c|c|}
\hline Asleep and day-time dozing & $\begin{array}{c}\text { Clerks } \\
500\end{array}$ & $\begin{array}{c}\text { Miners } \\
49^{\circ}\end{array}$ \\
\hline Activities when not at work & I410 & 1420 \\
\hline Activities at work & 890 & 1750 \\
\hline Total & 2800 & 3660 \\
\hline
\end{tabular}

Table 3 gives theoretical figures for a similar division of activities for a clerk completely sedentary at work, the FAO reference man and a worker in heavy industry. The FAO reference man forms the basis whereon the FAO: Committee on Calorie Requirements (1950) assessed physiological needs. He was defined by the Committee as follows:

"The reference man is 25 years of age. He is healthy, i.e. he is free from disease and exhibits a "normal" degree of physical fitness. He weighs 65 kilograms and lives in the temperate zone at a mean external annual temperature of $10^{\circ} \mathrm{C}$. He consumes 
an adequate, well-balanced diet; he neither gains nor loses weight. His activity is exemplified by the following average weekly schedule: on each working day, 8 hours of physical work of the type referred to below, 4 hours of "sedentary" activity (e.g. reading, writing), a walk of 5 to 10 kilometers on the level, and at least 2 hours out of doors; on each nonworking day, the active pursuit of exercise and sport not of the extremely strenuous variety. The degree of activity involved in occupation in light industry, driving a truck, dairy farming or market gardening, or general laboratory work would represent approximately his working activity.

In the judgement of the Committee, a man as defined above needs, on an average for the entire year, 3,200 calories daily'.

\section{The three components of energy expenditure in daily life}

I want now to discuss the difficulties of assessing and measuring these three components of the energy expenditure in daily life and some of the variations in calorie needs that may arise.

Energy expenditure asleep and in bed. There is little doubt that the basal metabolic rate (B.M.R.) reflects accurately the overall energy expenditure throughout the night. Passmore \& Durnin (1956) have discussed the evidence for this at length. Further, the great majority of persons spend approximately 8 out of the $24 \mathrm{~h}$ in bed. The exact time can be easily recorded and so, if the B.M.R. is known, this component of the energy expenditure can be calculated. There is a vast literature on the effect of age, sex, body size, climate and race on the B.M.R. Many thousands of individual data have been subjected to statistical analyses and a diversity of conclusions drawn as to the effects of these variables. Now the point that I wish to make is that it is unprofitable to spend much time in disputing the relative merits of different ways of expressing standards of normality for the B.M.R., when attempting to assess calorie needs of populations. The simplest standards are probably the best. None of the methods are likely to be in error by more than $\pm 10 \%$ and most by less than $\pm 5 \%$. This involves a total error of 25 or at most $50 \mathrm{Cal}$. a day in the sleep component of the energy expenditure. Such an error is negligible in comparison with the errors involved in the other components. Energy expenditure asleep or in bed can be accurately assessed. For most men, weight $65 \mathrm{~kg}$, it will be around 500 Cal./day.

Table 3. Expenditure of energy (Cal.) for a day's work by a hypothetical very sedentary clerk, by the $F A O$ reference man and by a hypothetical heavy worker (all aged 25 years, weight $65 \mathrm{~kg}$ )

Asleep or in bed

Activities when not at work

Activities at work

$\begin{array}{ccc}\begin{array}{c}\text { Sedentary } \\ \text { clerk }\end{array} & \begin{array}{c}\text { FAO } \\ \text { reference }\end{array} & \begin{array}{c}\text { Heavy } \\ \text { wan }\end{array} \\ 500 & 500 & 500 \\ 1500 & 1500 & 1500 \\ 800 & 1200 & \text { Up to } 2400 \\ 2800 & 3200 & \text { Up to } 4400\end{array}$


Energy expenditure at work. Table 3 gives the extreme limits. Even the most sedentary clerk occasionally walks across the office. The figure of $800 \mathrm{Cal}$. per $8 \mathrm{~h}$ day corresponds to an overall rate of $\mathrm{I} \cdot 67 \mathrm{Cal} / \mathrm{min}$, a figure some $60 \%$ above the B.M.R. It is just above the mean value, which we obtained experimentally for clerks when sitting at work (Garry et al. 1955). The upper limit of $2400 \mathrm{Cal}$. for a heavy worker is based upon the views of German industrial physiologists (Lehmann, 1953; Müller, I953). They have pointed out that a gross energy expenditure of $5 \mathrm{Cal} . / \mathrm{min}$, corresponding to an oxygen consumption of almost I $1 . / \mathrm{min}$, is the upper limit of rate of overall work that can be maintained without signs of cumulative fatigue appearing. Such signs are a rising pulse rate or a steadily rising body temperature or a gradual accumulation of lactic acid in the blood. The German workers maintain that a healthy man should be able to work at an overall rate of $5 \mathrm{Cal} / \mathrm{min}$ for $8 \mathrm{~h}$ a day, 6 days a week and 50 weeks a year without evidence of cumulative fatigue. To me this seems a sensible upper limit of what may be expected of any healthy man in heavy industry. Lumber-men and others, of course, have been reported to have worked at much higher rates for long periods. Such men are probably not 'normal' and have been self-selected for the job. Further, lumber work is seasonal and the periods of very hard work are punctuated with weeks or months of relative inactivity.

Where most men come in the range $800-2400 \mathrm{Cal} /$ day at work, it is difficult to say. No doubt many more approximate to the lower extreme than the upper. It is seldom recognized to what extent homo sapiens has become homo sedentarius. Miners and military cadets might be expected to be the most active of people, yet they spent $8 \frac{1}{4} \mathrm{~h}$ and $9 \frac{1}{4} \mathrm{~h}$ each day sitting (Garry et al. 1955; Edholm et al. 1955). In Table 3, I have arbitrarily broken up the reference man's $3200 \mathrm{Cal}$./day and attributed $\mathrm{I} 200 \mathrm{Cal} /$ day to work. This I think is a sensible figure for 'light industry, driving a truck or general laboratory work'. It is less difficult to be confident about 'dairy farming or market gardening'. Indeed although more people in the world are employed in agriculture than in any other industry, we know little about overall rates of energy expenditure. Certainly at harvest time without mechanical power men and women work very hard (see Passmore \& Durnin, I955). But agricultural work is seasonal and, especially in the tropics, there are long periods when the labourers are relatively inactive. On a modern mechanized farm, much of the work may be sedentary. It would be very interesting to have records of the daily energy expenditure of farmers at different seasons of the year. From the varied and manifold nature of their activities, such data would be very difficult to obtain. I guess that the figure of $1200 \mathrm{Cal}$./day given for the reference man would not be far out for the average for farm workers throughout the year in many countries.

Energy expenditure when not at work. This is perhaps the component of the three parts of the $24 \mathrm{~h}$ activity in which individuals vary most. It is also the one which has been least studied. Many men spend much time getting from home to their working place in the morning and back again in the evening. For some this daily travel may involve a considerable expenditure of energy; but their number is now decreasing with the great increase of 'buses, cars and trains in all countries. Opportunities for outdoor sports, games and hobbies vary greatly. Some indoor recreations, such as 
dancing, may involve much physical activity. Most men spend about $\mathrm{I} h$ a day dressing, undressing, shaving and on other 'personal necessities'. This category usually involves about 200 Cal. (Passmore \& Durnin, 1955).

Women probably spend more time in this way. Here I must belatedly apologise for considering here only the male members of society. Limitations of time must be my main excuse. However, there are much fewer data for women and any estimates of their daily energy expenditures must be based on even more tenuous evidence than those for men.

Table 2 shows that both the miners and the clerks, whom we studied, expended on an average just over $1400 \mathrm{Cal}$./day, when not at work. In Table 3 the arbitrary figures have been set at ${ }_{5} 500 \mathrm{Cal}$ /day. This is because the reference man of 25 years was a little younger than our average subject. I suspect that age has a big effect on this component, though I know of no measurements to give a quantitative guide to the decline in activity with the years. The small decline in the B.M.R. as age advances may reduce by up to I00 Cal./day the energy expenditure during a period of $8 \mathrm{~h}$ sleep. Durnin ( $195^{6}$ ) discusses the effect of age on energy expenditure at work. The pace of work is in many occupations determined by the nature of the work and the other workers. The older man usually has to keep up-or find an easier job. However, if he is tired, the older man can rest at home after the day's work. Some young persons, adolescents and those in their twenties, often appear to have an inexhaustable supply of energy to work off in their free time, in the evenings and at week-ends. Much depends on the opportunities for physical recreation; if these are good, then ${ }_{5} 00 \mathrm{Cal}$./day may well be an underestimate of energy expenditure when not at work for a man aged 25. By the age of 35 most men have curtailed greatly their physical recreations and by 45 few take part in strenuous sports. This sharp decline in strenuous recreations with age, is probably very much greater than the decline of energy expenditure both at work and asleep.

Climate of necessity plays a part in determining recreations. The short hours of winter daylight limit opportunity. Cold weather also limits the variety of possible recreations and may lead to disinclination to be out of doors. It is well known that in Great Britain people are most likely to take an active part in sports during the height of the summer. The Mediterranean climate is also well known to be ideal for most sports. It was my experience in India and in Egypt that only on occasions in the summer did the extreme heat curtail physical recreations. Indeed in India those who have the economic means usually take part in active physical recreations throughout the year. Probably climate plays little part in the extent of physical recreation except at the two extremes - the very cold and the very hot-both of which curtail energy expenditure. If this is so, then the FAO committee were probably in error in allowing a decrease of $5 \%$ in calorie requirements for every $10^{\circ}$ of mean annual temperature above the reference temperature of $10^{\circ}$ and a similar increase of $5 \%$ in calories for every $10^{\circ}$ below the reference. The Committee reached these conclusions by accepting (provisionally) data obtained by dietary studies on American soldiers in various parts of the world. These data showed a linear fall in calorie intake with a rise in environmental temperature. Social and other 
factors (such as changes in body-weight) may be alternative explanations of this fall.

\section{The effect of body size}

Most of the physical work which we do consists in moving our body about. There is, therefore, a close relation between individual body-weights and rates of energy expenditure. For some activities, such as standardized stepping (Mahadeva, Passmore \& Woolf, I953), individual energy expenditure is directly proportional to body-weight. When much external work is done, as in shovelling coal, the relationship is much less close. In walking a major part of the energy expended is used to lift the body at each step. Weight also plays a big part in determining the B.M.R. Height also contributes, but probably no significant error in calculating the metabolism when asleep arises if height is neglected. At work, during recreations and asleep, weight is the dominant factor determining individual variation in energy expenditure. The FAO Committee suggested that the relationship between calorie needs $(\mathrm{E})$ and body-weight $(\mathrm{W})$ could be expressed as:

$$
\mathrm{E}=\mathrm{aW}^{0.73}
$$

where a is a constant. This is admittedly a guess, but it is a guess based on considerations of a large number of estimations made on individuals under a variety of standardized experimental conditions. It is in fact an excellent example of a 'guestimate' -and in my opinion a most useful and practical one.

Though there is every reason to think that this formula gives a practical expression of the relation between energy expenditure and weight for healthy persons of approximately normal body composition, there is no justification for applying it to individuals who are very fat or very thin or indeed to a person who in any way deviates markedly from the normal size or shape.

\section{A practical consideration}

There is no need for me to emphasize how common obesity is in Great Britain. We are all familiar with the problem. The treatment of obesity is a matter of great difficulty. In a recent study in Boston (Bowser, Trulson, Bowling \& Stare, 1953) three large groups of obese persons were (a) left untreated, (b) referred to a hospital dietary clinic, (c) subjected to group dietary therapy. After 2 years no difference was apparent between the groups and, generally speaking, there was no improvement. Immediate loss of weight at the beginning of the various treatments, was not permanent. Similar disheartening experiences must be familiar to all of us.

I suggest that in homo sedentarius the dietitian is presented with an impossible problem. As Mayer ( 1955 ) has pointed out, the hard environment, in which mankind has developed, has made men physically active, resourceful creatures, well prepared to be hunters, fishermen or agriculturalists. Our appetite was never designed as a food-regulating mechanism for persons who spend most of their lives seated on a chair. Perhaps there may be a minimal rate of daily energy expenditure for each one of us; above this minimum rate, appetite is a good guide to food intake: below 
appetite may often mislead. If this is so, then the first object in the treatment of obesity should be to get the patient active and increase the daily energy expenditure. Too little attention is paid to this nowadays. In the past it has often been stated that by walking hard for half an hour in the morning and again for half an hour in the evening an obese person may burn off I oz. fat. This fact has been well publicized, and the effect is disheartening. If, however, the procedure is continued for a year, then over $20 \mathrm{lb}$. of fat or its equivalent will have been oxidized. This amount is not negligible. More important, this regular increase in daily energy expenditure may set the appetite-regulating mechanism aright and thereby provide the necessary conditions for the advice given by dietitians to be practical.

The sedentary nature of so much of modern industrial life necessitates a new appraisal of daily energy-expenditure rates. Much more attention is needed to the problem of the energy costs of recreations. Our Nutrition Society might begin in a practical way. I would suggest, in all seriousness, to members of the Programmes Committee who may be here that they no longer arrange our meetings on Saturday afternoons. This is a time when all of us might be employed expending calories more rapidly and to the betterment of health.

\section{REFERENCES}

Bowser, L. J., Trulson, M. F., Bowling, R. E. \& Stare, F. J. (1953). F. Amer. diet. Ass. 29, II 93. Durnin, J. V. G. A. (1956). Proc. Nutr. Soc. 15, 89.

Edholm, O. G. (1956). Proc. Nutr. Soc. 15, 80.

Edholm, O. G., Fletcher, J. G., Widdowson, E. M. \& McCance, R. A. (1955). Brit. F. Nutr. 9, 286.

Garry, R. C., Passmore, R., Warnock, G. M. \& Durnin, J. V. G. A. (I955). Spec. Rep. Ser. med. Res. Coun., Lond., no. 289.

FAO: Committee on Calorie Requirements (1950). F.A.O. mutr. Stud. no. 5.

FAO (1955). The State of Food and Agriculture 1955. Review of a Decade and Outlook. Rome: Food and Agriculture Organization of the United Nations.

Lehmann, G. (1953). Praktische Arbeitsphysiologie. Stuttgart: George Thieme.

Mayer, J. (1955). In Weight Control. Ames, Iowa: Iowa State College Press.

Mahadeva, K., Passmore, \& Woolf, B. (r953). Y. Physiol. r21, 225.

Müller, E. A. (1953). Quart. F. exp. Physiol. 38, 205.

Passmore, R. \& Durnin, J. V. G. A. (1955). Physiol Rev. 35, 801.

\section{Energy expenditure in the elderly}

\section{By J. V. G. A. Durnin, Institute of Physiology, University of Glasgow}

It is perhaps not immediately obvious why age itself should exert an independent effect on energy expenditure. May it not be that changes in weight or in surface area, with a different disposition in the mass of active tissue, are the chief means by which the energy output is altered?

For example, in a specific exercise one might think that energy expenditure would be related simply to, say, the weight of active tissue, such as muscle, as distinct from inactive tissue, such as bone and fat, and that, if results could be expressed as $\mathrm{Cal} . / \mathrm{kg}$ of this active tissue, then age might show almost no effect. This may indeed be true for any particular controlled exercise, such as lifting a load of moderate 